\title{
Mapping of aquaculture facilities in Yamada Bay in Sanriku Coast, Japan, by IKONOS satellite imagery
}

\author{
TERUHISA KOMATSU ${ }^{1}$, MASAHIRO TAKAHASHI ${ }^{2}$, KENICHI ISHIDA $^{1}$, TAKASHI SUZUKI $^{2}$, TOMONORI HIRAISHI ${ }^{3}$ AND \\ HIDEO TAMEISHI $^{4}$ \\ ${ }^{1}$ Ocean Research Institute, The University of Tokyo, 1-15-1 Minamidai, Nakano-ku, Tokyo 164-8639, Japan \\ (komatsu@ori.u-tokyo.ac.jp), ${ }^{2}$ Mitsubishi Space Software Co., Ltd., World Trade Center Bldg., 2-4-1 Hamamatsucho, \\ Minato-ku, Tokyo 105-6137, Japan, ${ }^{3}$ Graduate School of Fisheries Science, Hokkaido University, 3-1-1 Minatocho, Hakodate, \\ 041-8611, Japan and ${ }^{4}$ Japan Fisheries Information Service Center, 4-5 Toyomicho, Cyuo-ku, Tokyo 104-0055, Japan
}

SUMMARY: Recently it is stressed that sustainable development is indispensable for fisheries. It requires rational use of the sea, especially in the coastal area. Since there are a lot of aquaculture facilities in coastal waters, it is necessary to localize and count them for management of coastal fisheries. Thus we developed an easy method to map and count them using IKONOS satellite image with high resolution. Processing IKONOS imagery of Yamada Bay, one of rias-type bays in Sanriku Coast, aquaculture facilities for scallops and oysters were analyzed. Two types of aquaculture facilities, wood-raft type and buoy-and-rope type, were identified and examined. The method developed in this study can be applied to not only rias-type bays but also other coastal waters.

\section{KEY WORDS: IKONOS, mapping, aquaculture, image analysis, coastal management}

\section{INTRODUCTION}

45

It is asked that states and users of living aquatic resources should conserve aquatic ecosystems for sustainable fisheries. In coastal waters, aquaculture (e.g. shrimp farming ${ }^{1)}$ ) has been developed in the world since 1980s. Therefore it is needed to establish databases and information norks to collect, share and disseminate data related to aquaculture activities to manage aquaculture facilities for sustainable development of coastal fisheries.

In Japan, aquaculture has been already developed since 1970s. A lot of aquaculture facilities are deployed in sheltered waters. For management of coastal fisheries, it is very important to know precisely where and how many aquaculture facilities are distributed. In Japan, fishermen's cooperatives manage practically fishing rights in coastal waters on behalf of a local government. Usually, a map of fishing right territory used for management depicts not positions of each fishing gear and facility but only zones of fisheries in coastal waters. When aquaculture facilities are numerous, it is difficult to map all. When more than one fishermen's cooperative exist in the bay, it is hard to map aquaculture facilities with the same method or at a same level of precision.

Satellite remote sensing has been developed for land use studies in agriculture but not for sea surface utilization studies in fisheries science. One of the reasons of less attention on the sea surface utilization studies using satellite remote sensing is attributed to low resolution of satellite imageries such as LANDSAT (resolution: $15 \mathrm{~m}$ ) and SPOT (resolution: $10 \mathrm{~m})^{2}$. Aerial photography, which has high resolution, has been used to analyze objects smaller than 10 $\mathrm{m}$. However, aerial photography requires a lot of time for geometric correction and mosaic processing of several scenes. When a target area is too large or many aquaculture facilities are distributed there, it is laborious to survey all area in a day using a boat because of time required. Even if a boat is available for field survey, localization of aquaculture facilities with GPS is unsuccessful in the cases that the boat can't approach to the aquaculture facilities.

IKONOS, launched on 24 September 1999, is the first commercial satellite with $1-\mathrm{m}$ resolution ${ }^{2)}$. Therefore it will be possible to make a precise distribution map of small-scale aquaculture facilities distributed in a broad spatial area in a short period if they can be identified. This paper aims to examine whether we can obtain information about the distribution of aquaculture facilities analyzing IKONOS imagery of a rias-type bay in Sanriku Coast where aquacultures of scallops and oysters are developed.

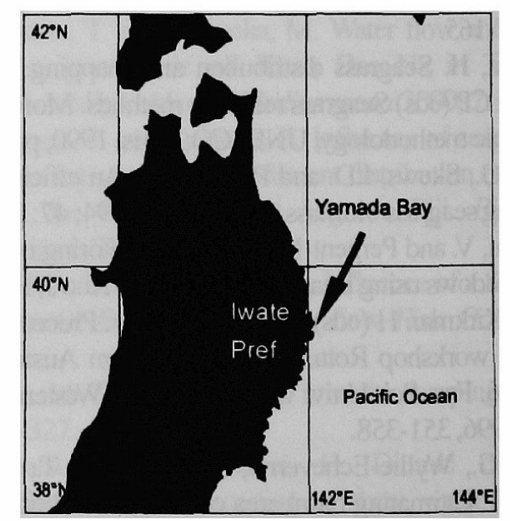

Fig. 1 Map showing Yamada Bay, Iwate Prefecture, along Sanriku Coast, Japan. 


\section{MATERIALS AND METHODS}

We selected Yamada Bay in Sanriku Coast (Fig.1) as a study site, which is one of the rias-type bays in Sanriku Coast facing the Pacific Ocean. Because the bay mouth is narrow, the inside of the bay are protected from waves and currents (Fig.2). There are a lot of aquaculture facilities in the bay. Thus the bay is suitable for the study site.

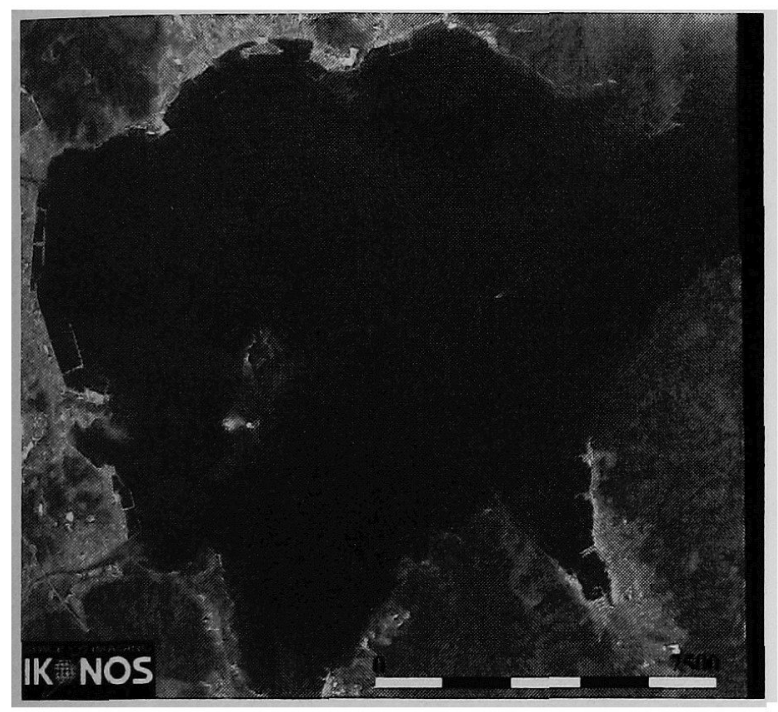

Fig. 2 IKONOS true color image on Yamada Bay on 17 July 2000. Bay mouth is situated northeastward of the image.

Field survey was conducted on 18 September 2001 to check the results obtained by image analysis of IKONOS imagery. Types of aquaculture facilities identified by image analysis were verified. Several aquaculture facilities of two types were localized with GPS (GARMIN, GPS-II plus).

IKONOS has a CCD (Charge-Coupled Devices) linear array as a photo sensor, which scans wave bands between $0.45 \mu \mathrm{m}$ and $0.9 \mu \mathrm{m}$. Panchromatic and multi-band images are processed from data of above-mentioned band. The former is composed of all bands. The latter are infrared, red, green and blue images dividing the bands into four band widths, respectively. One pixel of IKONOS imagery represents data ranging between 0 and 2047 gradients processed by $\mathrm{AD}$ converter of 11 bits.

This study used two types of pan-sharpend images (Fig. 2) cut off from IKONOS imagery taken on an area of Iwate Prefecture including Yamada Bay on 17 September 1999. Two types of pan-sharpend images, true (red, green and blue) and false color (infra red, red and green), were processed synthesizing panchromatic image of $1 \mathrm{~m}$ resolution and multi-band color images. The longitudinal and latitudinal distances of the images were $11228 \mathrm{~m}$ and $8000 \mathrm{~m}$, respectively. File size of each image was 538MB. Images were analyzed with two software: eCognition
(Definiens Imaging $\mathrm{GmbH}$ ) and TNTmips (Microlmages, Inc.)

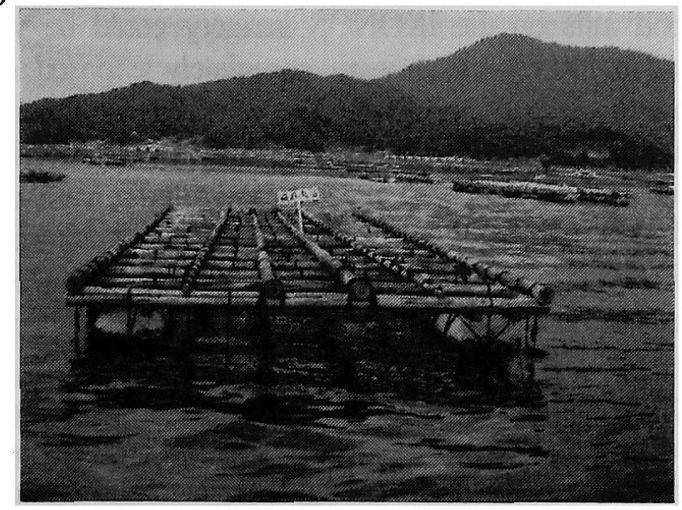

Fig. 3 Wood-raft type aquaculture facility in Yamada Bay.

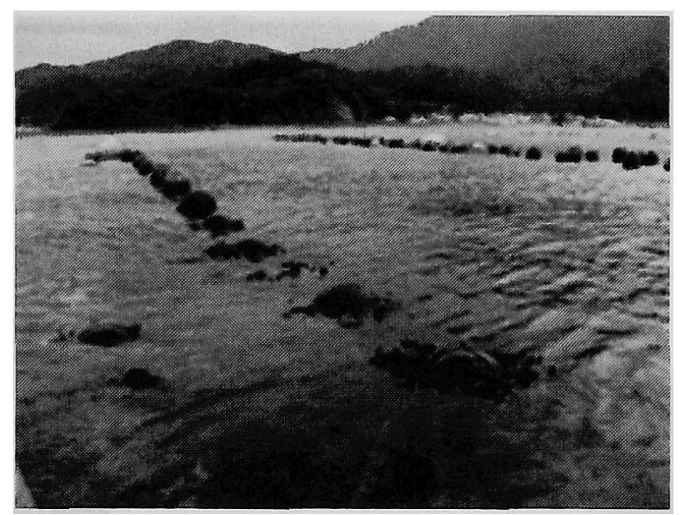

Fig. 4 Buoy-and-rope type aquaculture facilities in Yamada Bay.

\section{RESULTS AND DISCUSSION}

\section{Field survey of aquaculture facilities}

Fishing right territory in Yamada Bay was divided by three fishermen's cooperatives, Yamada, Ohsawa and Ohura. Aquaculture facilities were classified into two types: wood-raft type and buoy-and-rope type. Fishermen used two types of facilities for scallop and oyster aquaculture. Aquaculture license of the former type by Iwate Prefecture stipulated for the size of the raft; it was rectangular and its length and width were $12 \mathrm{~m}$ and $4 \mathrm{~m}$, respectively (Fig. 3). On the other hand, aquaculture license of the latter type stipulated not for size and color of buoys but for rope length (Fig. 4). Clusters of oysters or scallops were attached to vertical rope, which was suspended from the raft or buoy-and-rope facilities. The length of horizontal rope ranged between 50 and $100 \mathrm{~m}$. Number, size and color of buoys depended on a facility. We compared positions of representative rafts and buoy-and-rope facilities localized by image analysis with those by GPS in situ. Differences in positions localized with both methods were within several meters equivalent to those of errors of GPS. 


\section{Distribution of wood-raft type facilities}

Wood rafts on the IKONOS imagery could be visually counted because they were completely exposed on the seasurface. In this study, we used the software that identified and counted automatically the wood rafts (Fig. 4). Iwate Prefecture licensed 3035 wood rafts in Yamada Bay in 1999-2000 while image analysis extracted automatically 3057 wood rafts (Table 1). There was no difference in the number of licensed wood rafts from 1999 to 2001 according to Ohsawa Fishermen's Cooperative. The field survey discovered that about 20 wood rafts were moored near the coast in Yamada Bay as reserve rafts in a case of breakage accident of rafts. These results show that it is accurate to count wood rafts in Yamada Bay by image analysis of IKONOS imagery.

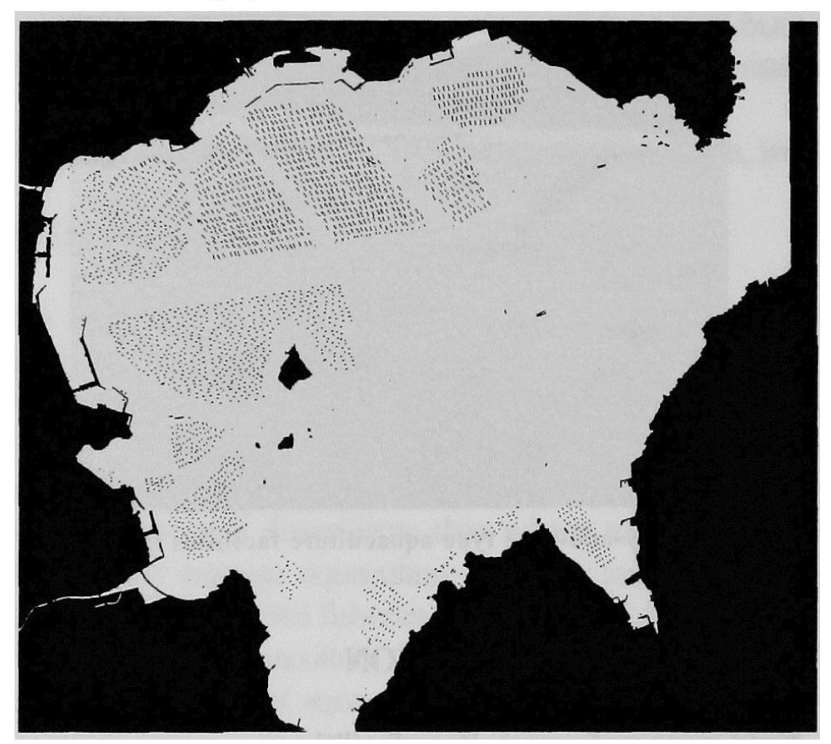

Fig. 5 Distribution of wood-raft type aquaculture facilities in Yamada Bay.

Table 1 Number of wood rafts and their individual surface area in Ymada Bay obtained by image analysis.

\begin{tabular}{ccc}
\hline $\begin{array}{c}\text { Parameter of } \\
\text { Wooden raft type }\end{array}$ & Registered raft number & IKONOS image analysis \\
\hline Total number & 3035 & 3057 \\
$\begin{array}{c}\text { Surface area } \\
\text { of individual raft }\end{array}$ & $\begin{array}{c}48.0 \mathrm{~m}^{2} \\
(12 \mathrm{~m} \times 4 . \mathrm{m})\end{array}$ & $\begin{array}{c}\text { Ave } 63.2 \mathrm{~m}^{2} \\
\text { Standard dev. } 4.92 \mathrm{~m}^{2} \\
(\mathrm{n}=3057)\end{array}$ \\
\hline
\end{tabular}

We evaluated an error of surface area of raft measured by image analysis of IKONOS imagery. The license of Iwate Prefecture determined the size of raft was $48 \mathrm{~m}^{2}(12 \mathrm{~m}$ $x 4 \mathrm{~m}$ ). Ohsawa Fishermen's Cooperative controls severely the size of raft. Controllers measure the length of each $\log$ of the raft and stamp sections at both ends of $\log$ when the log length corresponds with the regulation. The other cooperatives also control the size of wood rafts. Thus we measured the surface area of the rafts. Since the resolution of one pixel of IKONOS imagery is $1 \mathrm{~m}^{2}$, one raft is nominally consisted of 48 pixels. In reality, average surface area of raft measured by image analysis was 63.2 pixels, $63.2 \pm 4.9 \mathrm{~m}^{2}$ (Table 1). It is known that image analysis of satellite imagery overestimates a plane area of object with strong reflectance due to light diffusion. If the length is overestimated by 1 pixel at each side of raft, the surface area of raft becomes $65 \mathrm{~m}^{2}(13 \mathrm{mx} 5 \mathrm{~m})$. It is also true for rafts in Yamada Bay because they had relatively strong reflectance.

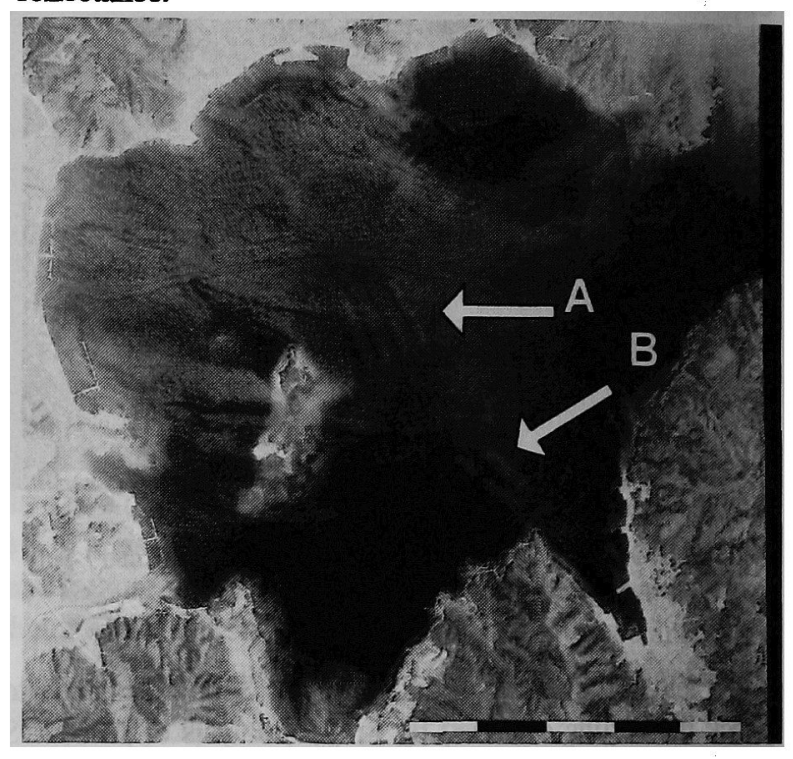

Fig. 6 IKONOS imagery enhanced to identify buoy-and-rope type aquaculture facilities (white arrows). $A$ and $B$ show type $A$ and type $B$ of aquaculture facilities, respectively.

\section{Distribution of buoy-and-rope type aquaculture facilities}

Although a buoy-and-rope type aquaculture facility had many buoys for getting buoyancy, it was difficult to identify the length of facility with image analysis of true color IKONOS imagery. Buoy-and-rope type aquaculture facilities in Figure 6 were clearer than those in Figure 2 due to enhancement of image characteristics through adjustment of color tone levels. They were distributed east and south of the island in the center of Yamada Bay. Buoy-and-rope aquaculture facilities were classified into two types based on the enhanced image: Type A and Type B were the buoy-and-rope aquaculture facilities whose total length could be measured (Fig. 7) and not measured (Fig. 8), respectively. Iwate Prefecture gave licenses of type A facilities to fishermen under the condition that the rope 
length was $60 \mathrm{~m}$. Image analysis showed that the rope length of type A facility was $58.4 \pm 3.3 \mathrm{~m}(\mathrm{n}=208)$. The result was nearly equal to the licensed condition of type $A$ facilities. Licensed number of type A was 210 in Yamada Bay in 1999-2000 while image analysis counted 208 type A facilities. Because the difference in number of type $A$ was under $1 \%$, image analysis is considered to be quite reliable and practical for counting the type $A$ facilities.



Fig. 7 Buoy and rope aquaculture facilities of type A whose length can be measured from the image.



Fig. 8 Buoy-and-rope aquaculture facilities of type B whose length can't be measured from the image.

Type B facilities included two kinds of rope lengths: $80 \mathrm{~m}$ and $50 \mathrm{~m}$. Field observation showed that these kinds of facilities were composed of black buoys and their diameters
Table 2. Buoy-and-rope aquaculture facilities of type B.

\begin{tabular}{ccc}
\hline \hline $\begin{array}{c}\text { Parameter of } \\
\text { buoy-and-rope }\end{array}$ & Officially registered data & IKONOS image analysis \\
\hline Total number & 648 & (Total area 367979m²) \\
Indivisual length & $80 / 50 \mathrm{~m}$ & Non-measurable \\
\hline
\end{tabular}

between 0.4 and $1 \mathrm{~m}$. Since the buoys were smaller than 1 $\mathrm{m}$ below the resolution of IKONOS satellite, it was difficult to distinguish them by image analysis. In some cases, suspended clusters of scallops or oysters were so heavy that buoys were submerged under the sea (Fig. 3). On the other hand, the surface area occupied by Type B facilities could be measured. It was $367979 \mathrm{~m}^{2}$ in Yamada Bay. Iwate Prefecture gave 648 licenses of type B to the fishermen in Yamada Bay in 1999-2000. Thus the mean surface area per one type B facility was $568 \mathrm{~m}^{2}$. Supposing that rope length was $80 \mathrm{~m}^{2}$, one side of rectangular surface area occupied by type $B$ becomes about $7 \mathrm{~m}$. It was observed that the interval of type B facilities was about 5-10 m in Yamada Bay. This suggests that the estimation of surface area occupied by type $B$ facilities is realistic.

\section{CONCLUSION}

It is verified that the image analysis can obtain information on distribution of small-scale aquaculture facilities including aquaculture facility types in the rias-type bay in Sanriku Coast from the IKONOS imagery. These results suggest that image analysis of IKONOS imagery serves as a tool for management of coastal fisheries for the long-term conservation of coastal environment and sustainable use of fisheries resources. This method is applicable to monitor small-scale fishing gears and aquaculture facilities not only in rias-type bays but also in any coastal waters.

\section{ACKNOWLEDGMENTS}

We thank to Mr. Kouichi Morita of Otsuchi Marine Experimental Station, The University of Tokyo, Mr. Jun Michimata of Ohsawa Fishermen's Cooperative and Mr. Shigeyoshi Ueyama of Japan Space Imaging Co. for their help during this study.

\section{REFERENCES}

1. Katsuky N, Römbäck P, Tedengren M. Ecosystem perspectives on management of disease in shrimp pond farming. Aquaculture 2000; 191: 145-161.

2. Jensen JR, Cowen DC. Remote sensing of urban/suburban ifrastructure and socio-economic attributes. Photogrammetric Engineering \& Remote Sensing 1999; 65: 611-622. 